\title{
The Extent of Child Trafficking and National Response in Ethiopia: A Quantitative Study
}

\author{
Aden Tolla and Shanta Singh ${ }^{*}$
}

\author{
Discipline of Criminology and Forensics Studies, School of Applied Human Science, University of KwaZulu- \\ Natal, South Africa
}

\begin{abstract}
This article analyzes the extent of child trafficking from a quantitative standpoint. The quantitative research approach was adopted in this study, supported by the application of cross-sectional exploratory and descriptive research design, which was used to address the extent of child trafficking in Ethiopia. A total of 636 household respondents were selected by systematic random sampling technique to fulfil the adopted quantitative survey. Data analysis was carried out using Statistical Package for Social Sciences (SPSS) version 24.0 statistical software packages. Adapt QuantitativeLogistic Regression, Bivariate analysis, Multivariate analysis, and Cross-tabulation of extent and factors of child trafficking were thoroughly quantified.

The extent of child trafficking from the total result in the study area is about 128 children had been trafficked from the total of 636 households and that means the extent of child trafficking is about 20.1 percent in East Este Woreda and Debre Tabor woreda in or 1 child from 5 children had been trafficked. It recommended, the research is needed to identify the extent of child victims and vulnerable of trafficking in the study area to combat the problem. On the other hand, for a clear understanding of the International Conventions and Treaties (such as fully translating Rights of the Child and all ratified conventions), the publication should be translated to Amharic and Oromifa version (local language) in the official Negarit Gazeta of Ethiopia, so that everyone could understand and seek to implement their right easily. Information gup is a disadvantage for the nation, the government should use different programs on television and radio to address the issue.
\end{abstract}

Keywords: Child trafficking, Ethiopia, National response, Quantitative research method.

\section{INTRODUCTION}

This article is having been extracted from a Doctorate (Criminology and Forensics Studies). Thesis titled: Assessing the Extent of Child Trafficking and National Response in Southern Gondar, Ethiopia. The main objectives were to quantitatively determine the extent, associated factors, and effects of child trafficking by adapting a quantitative research method. However, adopting a quantitative research method to determine the extent of child trafficking and to explain the national response towards child trafficking in Ethiopia, using documentary research method [The central focus of this article].

The main study was conducted using a quantitative research approach. The employed research design and methodology are described and explained step by step by the researcher, including adopted the data collection methods, data analysis, study findings, conclusions, and recommendations. The ethical clearance for the main study was based on the following aspects: informed consent, confidentiality, and privacy of respondents have followed as the University of KwaZulu-Natal (UKZN) standards. Thus, this article attempts to give a deep analysis of adopting a quantitative research approach to determine the extent of child trafficking in Ethiopia.

*Address correspondence to this author at the Discipline of Criminology and Forensics Studies, School of Applied Human Science, University of KwaZuluNatal, South Africa; E-mail: Singhsb@ukzn.ac.za

\section{Research Operational Definition}

For this research study, "child" means a person who has less than 18 years old.

Child trafficking - for this specific research, refers to any movement or transportation of a child for exploitation, criminal activities, and forced marriage and as (Howard, 2012) describes, is the illegal movement of a person who is less than the biological age of 18. It is very significant to understand that child less than 18 years cannot give her or his consent. It means, even if a child is not forced or threatened, not abducted, not coerced, or betrayed, the child cannot officially give consent to be moved. Thus, both legal and illegal ways of transportation for any illegal means of activity are called child trafficking.

This can be further explained as follows: -

Child who less than 18 years old who migrated for work voluntarily or voluntarily is trafficking.

If the parents did not know where their child lives is; it is child trafficking.

And if the parents know where their children live and if the child is working; it is child trafficking.

- When children migrate or are trafficked for work or both work and learn it is child trafficking. 


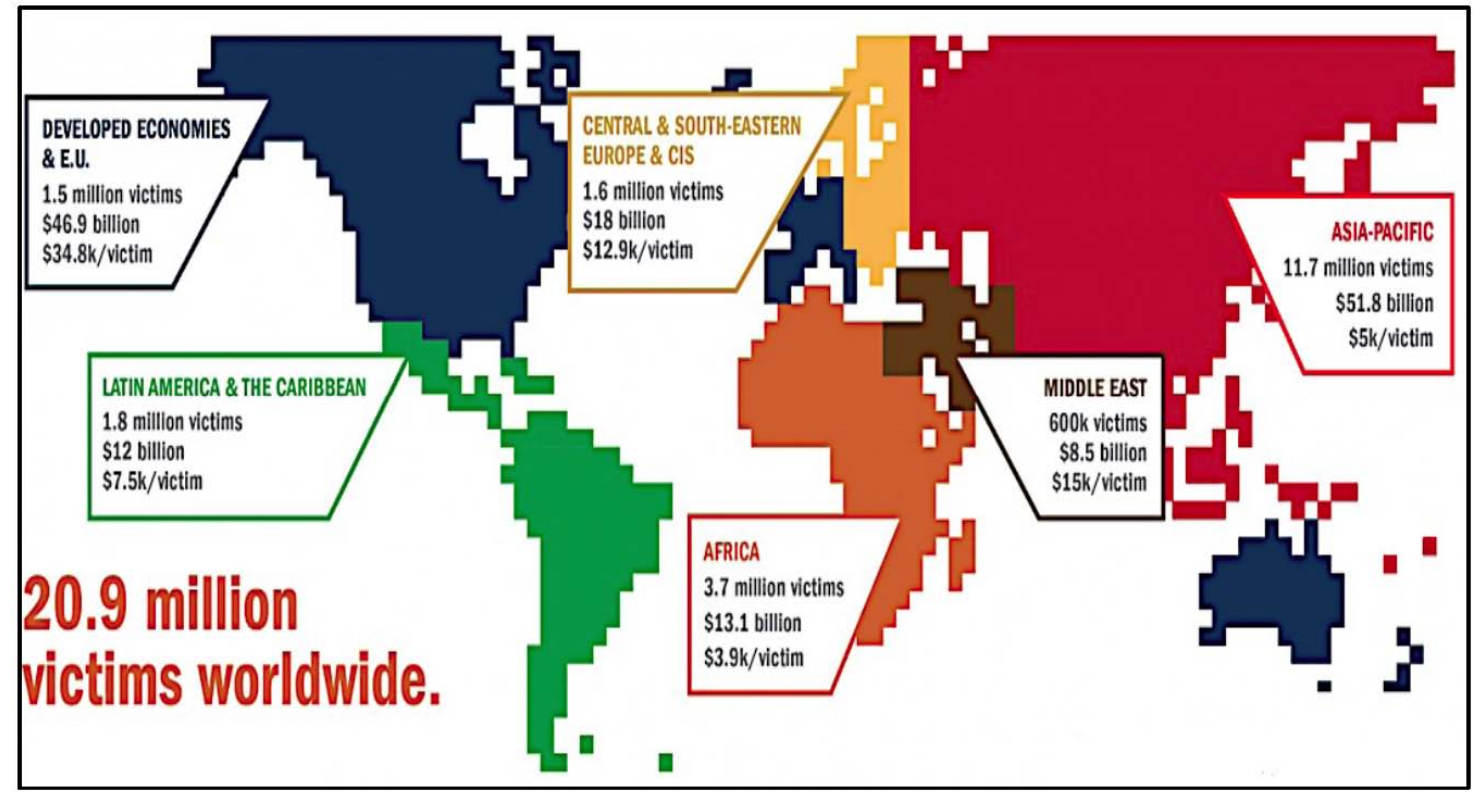

Figure 1: Victims and profit of human trafficking by region (Adapted from Wings of Shelter, 2017).

\section{BRIEF LITERATURE REVIEW: EXTENT OF CHILD TRAFFICKING AROUND THE GLOBE}

According to Assembly (2000), the United Nations Centre for International Crime Prevention has established data on global trends of trafficking. Even if the data is not widely available data on the responses of the criminal justice system, volume of trafficking in persons and migrants, volume and type of victims and offenders are available. Due to the international demand for cheap and undeclared labour, the request for children and women for the sex market, and large numbers of immigrants, this forms a profitable market for traffickers to engage in this criminal activity. Per UNICEF (2006) report in 2006, there are around 27 million victims of human trafficking worldwide, and out of it, approximately 50 percent of victims are under the age of 18. About 1.2 million children are traded internationally every year and about 300,000 children are at risk of the commercial sex industry (Fong and Berger Cardoso, 2010). Together with Chung's (2009) estimation that 30 million women and children have been trafficked in Asia for the past 30 years and about $80 \%$ are trafficked for sexual exploitation; 50 percent of victims being girls.

There are various ways in which children's rights can be violated (Wings of Shelter, 2017). In half the countries where records exist, more than 80 percent of children aged 2-14 have experienced violent discipline, while about a third of women aged 20 to 24 were married before the age of 18 . Figure 1 represents the regional human trafficking victims' profile and the profit generated by each region. Child labour affects 168 million children and around half are involved in hazardous work (Figure 1). According to Figure 1, there are about 20.9 million victims are available worldwide and Asia-Pacific and Africa have the big share. Whereas the profit generated in Developed Economies and European Union ( $\$ 34.8 \mathrm{k} / \mathrm{victims}$ ) and Middle East $(\$ 15 \mathrm{k} /$ victim) is higher than Asia-pacific ( $\$ 5 \mathrm{k} /$ victim) and Africa (\$3.9k/victim).

The regional proportion of trafficked adults and children is shown in Figure 2. Out of the yearly trafficked victims in the world, 55 percent of the victims are women and children, men and boys cover 45 percent, with the number of children underage victims estimated at 5.5 million (26 percent) as reported by (Human Rights First, 2017) (Figure 2). Children comprise about 28 percent of victims. The most detected victims are women, children, and men, in 2014. In the last 10 years, the profile of trafficking in person victims has changed positively.

\section{EXTENT OF CHILD TRAFFICKING CONTINENT CONCERN}

Human trafficking is recognised as a problem in more than 70 percent of the countries worldwide. Out of it one-third (33 percent) of countries are in East and Southern Africa (UNICEF, 2003). Trafficking is a recognised problem in at least 49 percent of African countries (UNICEF, 2006). The susceptibility of children and women to human trafficking is due to their assumed powerlessness, innocence, and inability to 


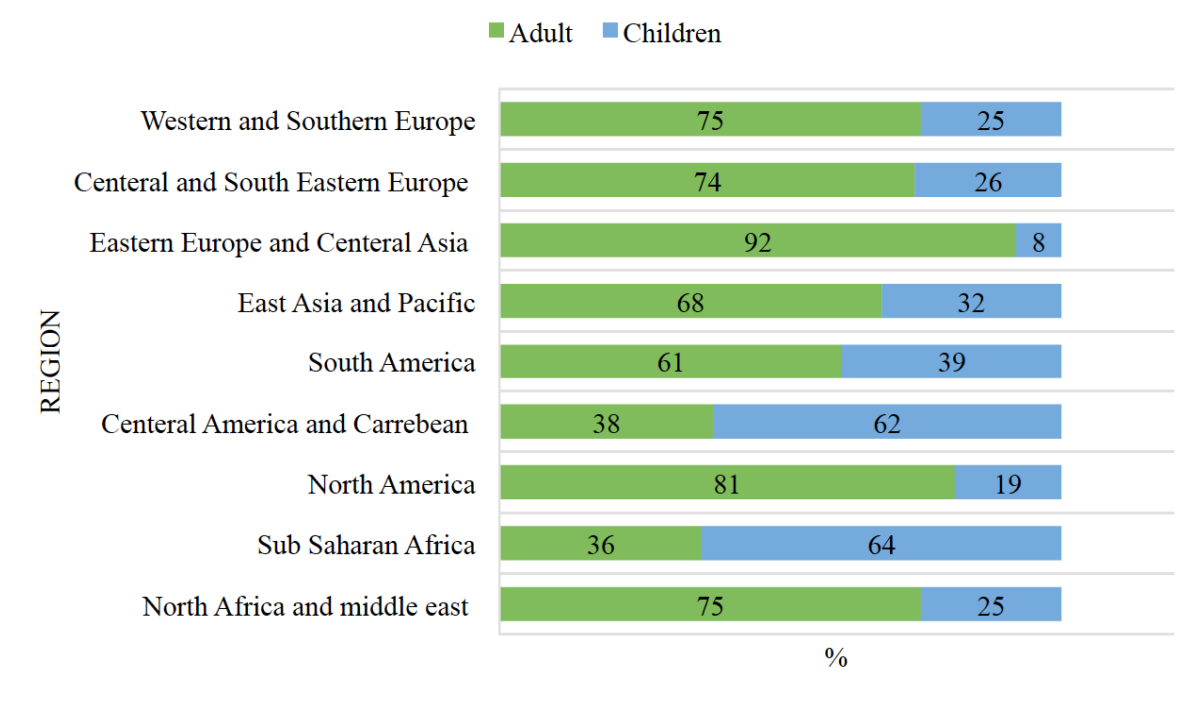

Figure 2: The regional proportion of trafficked adults and children (Adopted from UNODC, 2016).

protect themselves. Besides this, they are easier to manipulate and less able to claim their rights (Aronowitz 2009).

The new form of slavery by treatment and promise of victims for exploitation is the main way of trafficking Adepoju (2005). The increase in migrant smuggling and trafficking is observed in recent years, especially trafficking from Africa to Africa. The conventional wisdom is that 200, 000 children a year are trafficked in West Africa alone. West Africa is also the main source, transit, and destination country for trafficked women and children. The proportions of trafficked adults and children in selected African countries are depicted in Figure 3. As it is seen in the figure, Guinea, Nigeria, Uganda, and Lesotho are countries with a high extent of child trafficking (Figure 3). Trafficked children are recruited through networks of agents to work as domestic servants, in informal sectors, or plantations (Salah, 2004).

Child trafficking, all forms of exploitation, and forced labour are very common in Libya. About 1.7 million children under 14 years of age are exposed to victimisation under trafficking. Libya has been through civil violence and unrest for a long time. The civil violence and instability work to the advantage of traffickers and smugglers who easily cross the borders of Libya. The situation and condition aggravate the trafficking problem since there is no strong central government to control and protect the country from trafficking and it's impossible to combat and enforce anti-trafficking laws (Unites State Departments Office to Monitor and Combat Trafficking in Persons, 2015).
Similarly, Libya is an oil-rich nation that was controlled by a dictator, Muammar Gaddafi, before a civil war. However, even before his downfall, Libya was a magnet for human traffickers because of its geographical location (between Europe and SubSaharan Africa) and because Gaddafi's regime profited from trafficking. Women and girls are forced into the sex trade, and boys are recruited by militia groups. The geographical location of the largest African country, Algeria, serves as a transit country to the Sub-Saharan and middle east countries to get into Europe. All the Sub-Saharan African countries (South Sudan, Uganda, Ethiopia, and Congo) have very similar and common socioeconomic backgrounds, large populations, weak governments, instability, and civil violence.

All the Sub-Saharan African countries are sources, destinations, or transit regions for child and women trafficking (Unites State Departments Office to Monitor and Combat Trafficking in Persons, 2015). South and North Sudan are both the source and destination nations for human trafficking. Workers from Kenya, Uganda, Eritrea, Ethiopia, and the Democratic Republic of the Congo are brought into the nations by Sudanese people and employers to work in hotels, restaurants, and construction businesses. Generally, the Southern and the Northern part of the country have severe human trafficking problems. There are large market for child (10 years old and younger) slaves in Northern and Southern Sudan and girls exposed to the sex industry in the hotels, restaurants, and brothels. The common type of child abuse in Sudan includes market vending, construction, car washing, shoe shining, rock breaking, delivery cart pulling, brick making, and begging. 


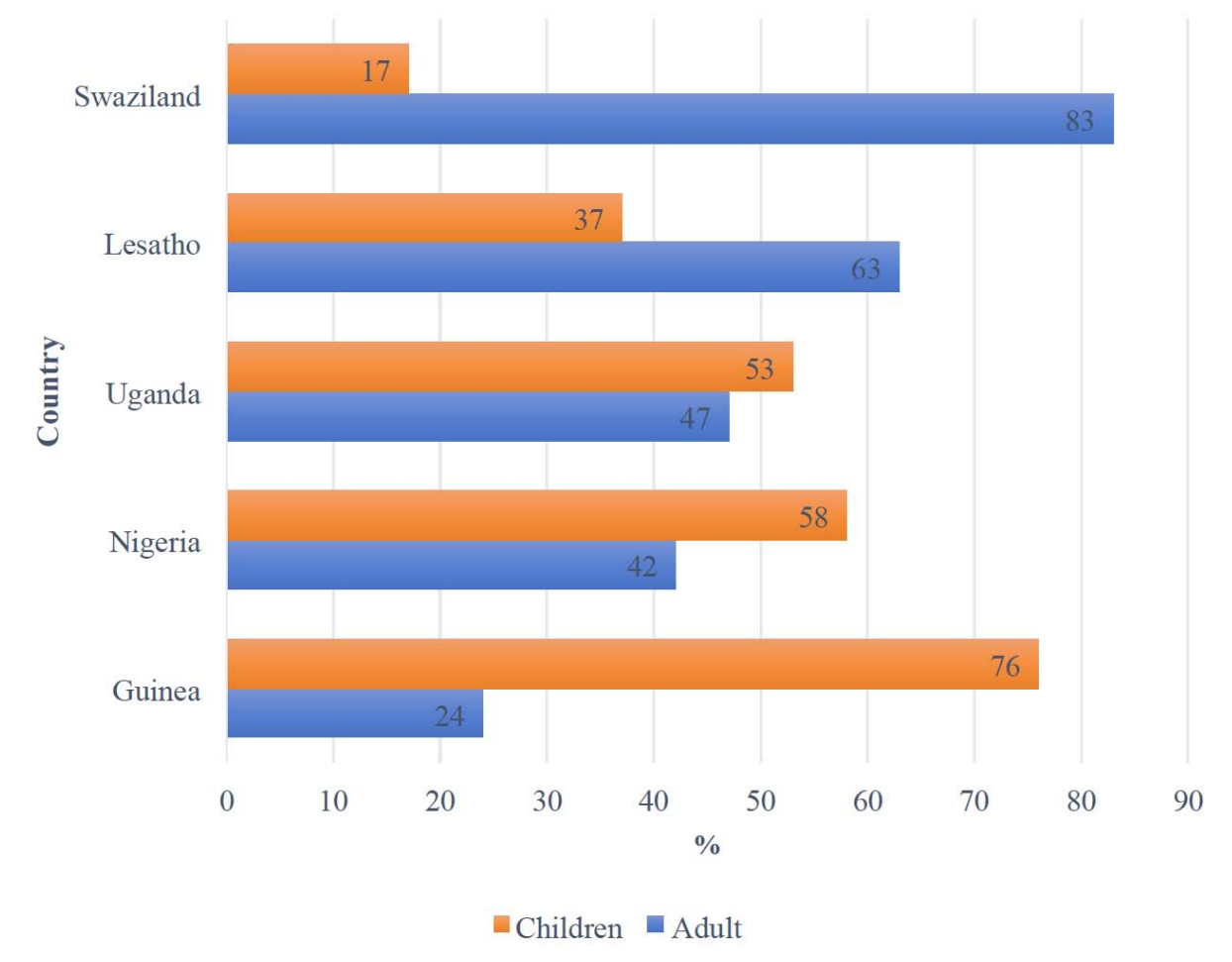

Figure 3: The proportion of trafficked adults and children in selected African countries (Adapted from UNODC, 2016).

\section{CHILD TRAFFICKING AND NATIONAL RESPONSE}

Ethiopia is a source, destination, and transit country for men, women, and children subjected to forced labor and sex trafficking. Internal trafficking to larger cities for domestic work exists, but the true extent of the problem is difficult to assess (Trafficking in person, 2019). Ethiopia is one of the most affected nations but very challenging to find out the extent of child trafficking. The most common factors for child trafficking are broken families, orphans or parents' death, and disintegration of immediate as well as extended families, under poverty and despair, parents are tempted to mobilize their children as resources to access immediate cash or long-term income (Tolla and Singh, 2018).

In Ethiopia, traffickers often deceive parents of children living in rural areas into sending their children to major cities to work as domestic workers. The traffickers promise families that the children will go to school and receive wages for their work, thereby enabling them to send money home (Trafficking in person, 2018). Information and communication factors (globalisation, factual awareness about trafficking, low awareness about their rights, and access to communication) are the contributing pull factors for child trafficking from this research study. Generally, the pull factors for child trafficking are multidirectional (Tolla and Singh, 2019).

The nation has started making efforts to minimise trafficking; however, it does not completely meet the minimum standards (Office to Monitor and Combat Trafficking in Person, 2016). Poor public awareness about child trafficking causes a low rate of prosecution in Ethiopia. Reports in Ethiopia points to the fact that low rate of prosecution of traffickers needs the attention of police investigation (Ethiopia, 2016). The human trafficking issue needs a network, a government with law enforcement and law enforcement agencies that encourage cooperatives with international networks to fight against trafficking practice in the place of the source, transit, and destination (Aronowitz, 2009). The expectation of cash and a better lifestyle on both parents and children side is very high, the financial constraints together with unrealistic expectations and desperation of parents make their children vulnerable to trafficking, as they are more likely to search for risky solutions and to have belief in false promises (Tolla and Singh, 2019).

The Socio-demographic factors (education, age, marital status, and geographical exposure) were found to be the factors for a child to be trafficked. Socioeconomic factors (poverty, unemployment, and parent 
disintegration) were found to be influential factors for child trafficking as well. There were socio- cultural factors (culture e.g., early marriage, parent poor childcare skill, gender inequality, gender violence, domestic violence, and seasonal factor) that influenced child trafficking in East Este and Debre Tabor Woreda from this research study. Economical poverty can be one factor for child trafficking in Ethiopia but not alone because child trafficking is very complicated and caused by different multidirectional factors like culture, belief, gender inequality, childcare culture, limited social service, gender inequality, and instability pushed children to be trafficked. The macro or social situation (current political situation) could also contribute factor for child trafficking (Tolla and Singh, 2019).

\section{International Instruments to Combat Child Trafficking}

Child trafficking is a global phenomenon that is not new. Rather, it is growing from year to year. The United Nations has the general and universal declaration on human rights internationally to all humankind and proclaims that everyone has the right to freedom without discrimination based on race, sex, color, religion, language, national or property political opinion, birth or another status, and social origin. The Universal Declaration of Human Rights and the United Nations has proclaimed that childhood is permitted to different care and assistance (UNICEF, 1989). All children have the right based on the conventions and charters, the responsible government should implement them according to those signed conventions and charts all over the world. Commitment and clarity on the conventions hold a vision of the future that all children will enjoy their childhood with all respected rights, with basic needs, non-violence, without abuse, exploitation, and neglect (UNICEF, 1994). Ethiopia did not implement the international conventions on human rights related to human trafficking due to the absence of capability, moral quality administration, and commitment (Hailu, 2015). The gaps in policies, legislations, and information dissemination campaigns within the prevention efforts were not effective as compared to the seriousness of the issue (Wakgari, 2014).

Children are highly vulnerable to human trafficking and targeted for human trafficking or trade because of their innocence, powerlessness, and not able to protect themselves. As they are easier to manipulate and unable to claim (Aronowitz, 2009). Nongovernmental organisations and international organisations have to compel the nations to ratify the legislation and treaties and make their contribution to fighting the trafficking problem (Lawrance \& Roberts, 2012). The United Nation Child Rights Committee/UNCRC comprises about 54 articles that govern children's rights and articulates how the governments must work together to make the articles obtainable to all children. Since it was adopted by the United Nations in November 1989, 194 countries have signed up to the UNCRC. All countries that sign up to the international law must ensure it is applied and this is supervised by the Child Rights Committee (Save the Children, 2017).

\section{UN Convention on the Rights of the Child (CRC)}

Nowadays, the three main legal supports of the child by 1989 UN Convention on the Rights of the Child (CRC), principles and its exact provisions are mainly in Article 32 which identifies the child's right "to be protected from economic exploitation" The UN General Assembly adopted the convention on 20 November 1989. Currently, 196 countries are part of it, including Ethiopia and every member of the United Nation.

\section{National Efforts to Combat Child Trafficking in Ethiopia}

According to Yosef (2016), Children are a vulnerable group in society; they need active protection on a national and international level. However, Ethiopian culture has "no room for the child." Children are part of a society that has no proper justice system to protect. Since Ethiopia has not combined CRC fully in the nation's Constitution or publish the full text of the CRC in the official Nagrit Gazeta, its problematic to implement accordingly with UNCRC (Yosef, 2016). Similarly (Woldemariam, 2011) the Constitution under article 36 is the only article with discussions of children rights, the best interests of the child, right to protection from cruel, non-discrimination, right to life, inhumane and degrading punishments, identity, and other basic children rights from its sub-article 1 up to sub-article 5 of this article. However, there is no clear legal provision under the constitution that discusses children regarding the right to be heard. Therefore, under the Constitution of FDRE, the right to be heard of the "Ethiopian children' remains elusive."

There are measures the Ethiopian government has put in place in trying to fight, control, prevent and address the child trafficking problem. However, these are not sufficient to deal with this problem, and as noted earlier government officials, including police 
officers, are major collaborators, facilitators, and benefactors of such practices, which raises the question of how any policy and regulatory framework would be effective without cleaning the rotten from the inside (Tolla and Singh, 2018). Under such conditions, despite the legal provision which takes the first line to render proper justice on brokers and facilitators of child trafficking in Ethiopia, and the child trafficking policies and legislations have proved to be not strong enough to prevent and protect, obviously there is a problem with implementation and direct assistance with victims. Ethiopia has verified all UN conventions and the nation is working with National Task Force to fight human trafficking. However, there is a big problem with implementation (Tolla and Singh, 2018).

\section{METHODOLOGY}

A qualitative research design for the study by using cross-sectional techniques and applied descriptive, inferential, and exploratory methods to understand the extent of child trafficking and contributed factors.

\section{Quantitative Research Method Approach}

This study applies quantitative research methods; non-experimental designs or descriptive designs are used to address the research questions. Probability sampling techniques are representative of the total population, the probability sampling technique was used to select the respondents, which were 636 study respondents were addressed. A systematic random sampling method was used in all parts of the study; two different locations (Este and Debre Tabor provinces), in the South Gondor area have been selected. Simple random sampling techniques were implemented to select 7 locations. The sample size distributes to the sampled location proportionate to the size of the households. Figure $\mathbf{4}$ represents the sampling procedure used during the study. From each location, the households were selected by systematic random method. The number and name list of the residents were available to select 636 study respondents so that the respondent's name was selected by systematic random sampling methods, which is by the interval of 20 household differences. And if the person from the selected household were not available during the data collection the next nearest household was included in the survey (Figure 4).

\section{Study Location and Population}

The research was conducted in the Federal Democratic Republic of Ethiopia, Southern Gondar of the Amhara National Regional in specifically Este and Debre Tabor province. The Ethiopian population is growing and comprises over 80 dissimilar ethnic groups in the country. Most people in Ethiopia speak

Sampling procedures

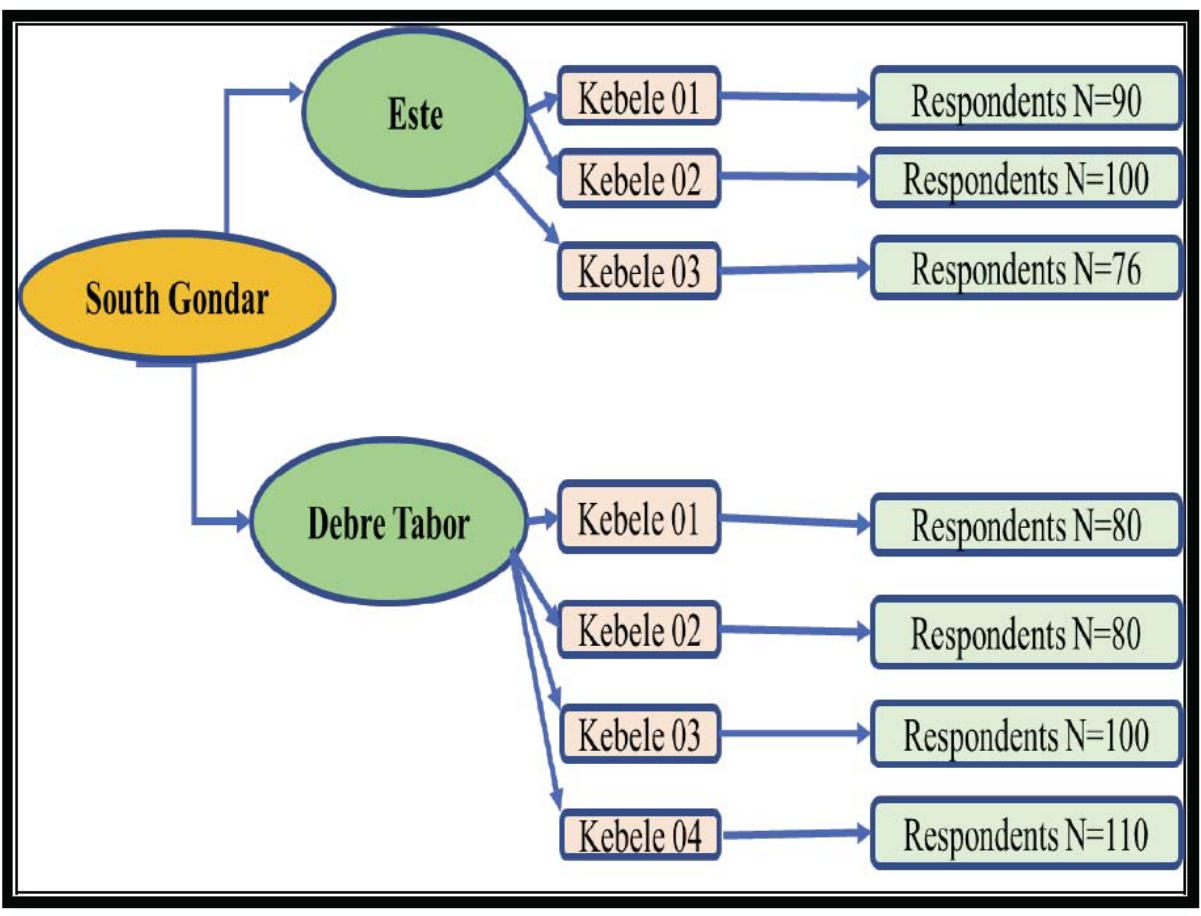

Figure 4: Crosstab analysis of child situation with the extent of child trafficking in Este and Debre Tabor, Ethiopia. 
Afro-Asiatic languages or Cushitic and Semitic in branches and Afro-Asiatic languages are the most spoken language. There are 90 different languages spoken in Ethiopia. The total population of Ethiopia was about 102,403,196 in 2016 (Demographics of Ethiopia, 2017).

The research was conducted in the Federal Democratic Republic of Ethiopia, Southern Gondar [Debub Gondar (Amharic)] of the Amhara National Regional in specifically Este and Debre Tabor province. It is found $678 \mathrm{~km}$ Northwest of Addis Ababa, the capital city of Ethiopia, and $113 \mathrm{~km}$ to the East of Bahir Dar, the capital city of the Amhara region. Debub Gondar (South Gondar) is a Zone in Amhara Region (South Gondar Zone, 2017). Based on the 2007 Census conducted by the Central Statistical Agency of Ethiopia (CSA), "this Zone has a total population of $2,051,738$, and an increase of 16 percent over the 1994 census, of whom 1,041,061 are men and $1,010,677$ women. With an area of $14,095.19$ square kilometers. The main ethnic group reported in Debub Gondar was the Amhara (99.7 percent); all other ethnic groups made up 0.3 percent of the population. 96.14 percent practiced Ethiopian Orthodox Christianity, and 3.68 percent of the population said they were Muslim" (South Gondar Zone, 2017).

\section{Target Population}

The target population of this article refers to all selected people or all selected individuals' whose biological age of more than 18 and residence in Este woreda and Debre Tabor Woreda, Southern Gondar of the Amhara National Regional State, Federal Democratic Republic of Ethiopia.

\section{Study Inclusive, Exclusive Criteria and Variables}

- Inclusive criteria: Any household in East Este woreda and Debre Tabor woreda are volunteers to participate.

- Exclusive criteria: Any person who is resident in Este selected in the distinct and person who has less than 18 years old.

\section{Study variables:}

- Dependent: Child trafficking practice in East Este and Debre Tabor woreda.

- Independent: Demographic factor, economic factors, cultural factors, education and awareness of the community, and protection strategies.

\section{Operational Definitions}

- A child means a person who has less than 18 years old.

- Child trafficking: The meaning for this specific research is that the transportation of a child for exploitation, criminal activities, and forced marriage. Howard, 2012 description of child trafficking is that an illegal movement of a person who is less than the biological age of 18 (with the years before 18 designated as a protective, economically inactive period).

- If the parents did not know where it is the child lives; is child trafficking.

- $\quad$ And if the parents know where their children live and if the child is working; is child trafficking. When children migrate or are trafficked for purpose of working is child trafficking.

- Information about child trafficking means if a respondent has any information or has heard about child trafficking before by any means.

\section{Sampling Method}

In this quantitative study, a total of 636 study respondents were addressed, Study households were selected by systematic random sampling technique. The sample size was calculated using the single population proportion formula. Since data is not available on the magnitude and associated factors related to the child trafficking in the study area, 50 percent of the population is used to determine the sample size based on single population proportion and the level of precision (d) is (0.05), as shown: -

$$
n=\frac{\left(Z_{\alpha / 2}\right)^{2} p(1-p)}{d^{2}}
$$

Accordingly,

- $\quad \mathbf{Z}$, which is the expected level of confidence, is 95 percent $/ 1.96$,

- $\quad \mathbf{P}$, which is the approximate proportion will be taken as 50 percent,

- d, the degree of accuracy required is 5 percent [Maximum] 
Therefore

$$
\mathrm{n}=\frac{(1.96)^{2} 0.05(1-0.05)}{0.05_{2}}=384
$$

The non-response rate which was estimated to be 10 percent of the respondents were included in the sample. Therefore, the total sample size $(n)$ was $=384$ $+(0.1 \times 384=39)$ for non-response rate $=423$ then multiply by design effect $423 * 1.5=636$. Therefore, the total sample size of this study is 636 , out of 39 different locations of South Gondar, data were collected from Seven [7] (20 percent) in different locations.

\section{Questionnaire Administration Process}

Self-developed questionnaires were developed based on the objective, literature review, and theoretical review. The questionnaire is prepared in English and translated into Amharic (Ethiopian national language) and translated back again to English for its consistency. Data was collected by using structured questionnaires.

\section{Method of Data Collection}

The data collection method was carried out via both primary and secondary (I.e. Questionnaire and documentary) methods. The quantitative research approach is structured in terms of what the researcher is looking for and want to find out about. The formulated questions are simple and pre-tested on the sample population from the same population background.

\section{Using Structured Questions: Empirical Evidence}

Data were collected by using the structured questionnaire or fixed response questionnaire. The procedure after selecting the 636 respondents by the interval of 20 names of households. Then the questionnaire was applicable by 20 household intervals $(1,20.40,60,80,100)$ according to the respondent's name list and house number if was applicable, which was provided by Kebele(location). About 40 individuals as data collectors participated. Two training were given before and after the pre-test for the validity of the questionnaires. In addition, they were trained on overall procedures of data collection. Questionnaires were checked by supervisors on daily basis for completeness. To keep the research ethical and academic, the researcher took every possible precaution to refrain from doing unethical work. The respondents were informed about the purpose of the study and the use of the data; the consent form was prepared on which both respondents and researcher signed. Data collection was based on the full consent of respondents.

The survey was conducted across 2 different woredas (Este (3 kebeles) and Debre Tabor (4 kebeles, refer to Figure 1) in Ethiopia. From both selected sampling locations, a total of 636 respondents participated. The data was collected within two months. Data collection was done by collaborating with one of non-governmental organisations in Amhara region, known as CHADET. Amhara region CHADET community workers in Este collected the data, and children and youth association from each kebeles of Debre Tabor are also participated to collect the data. The organization is working on child trafficking and related child social issues in Amhara region, Ethiopia.

\section{Method of Data Analysis and Management}

All descriptive, inferential, and exploratory methods were used to analyses the extent of child trafficking in the South Gondar region, the data was analyzed using Statistical Package for Social Sciences (SPSS) version 24.0 statistical software packages. This agrees with the study conducted by Agnarson (2006) in his/her study about Ethiopian immigration to Sweden. Based on the analysis of the collected data, the extent of child trafficking in the selected area to identify possible associated factors was analyzed. To achieve these aims logistic regression, bivariate analysis of factors association, multivariate analysis, and crosstabulation of factors associated with child trafficking were interpreted. The study interpreted the quantitative findings to provide a more comprehensive understanding of the extent, prevalence, and associated factors of child trafficking in Ethiopia. Then the researcher generalized based on the samples of the study, applied and discussed on the result of the research study by considering all populations in general.

The collected data was edited, coded, and cleaned before it is entered into a computer. Information from completed questionnaires was entered into a computer and analysed using SPSS version 24.0 statistical software packages.

\section{Methods to Ensure Validity Reliability and Quality Assurance}

The validity and reliability of the data were very important to the study before and during of data 
collection. The questionnaire was pre-tested among 5 $\%$ of the sample size selected from Southern Este province, which is not part of the main study, to make sure that the questions are cleared and can be understood by all the respondents. Then it was checked for its clarity, understandability, completeness, time, and pattern of response set problem. After the pre-test, some modifications were done to the questions to improve clarity. Amhara region CHADET community workers in Este and Children and Youth Association from each kebeles of Debre Tabor collected the data, with two training sessions given before and after the pre-test. Every day, the collected data was reviewed and checked for completeness and consistency by the researcher. The reliability of the study was checked using cleaning data and looking for missed questions and out-of-range values.

For quality assurance, the questionnaire was pretested among 5 percent of the sample size selected from Southern Este Worda, which is not part of the main study, to make sure that the questions are clear and can be understood by the respondents. Then it was checked for its clarity, understandability, completeness, time, and pattern of response set problem. Then some modifications were made to improve clarity. Every day, the collected data is reviewed and checked for completeness and consistency by the principal investigator. The reliability of the study was increased using cleaning data using initial frequencies and looking for missing and out-ofrange values.

\section{ETHICAL CONSIDERATIONS}

The research identified the methodological strategies that were used to accomplish doctoral research, focusing on assessing the extent of child trafficking in Ethiopia. Ethical consideration, full approval from UKZN protocol reference number HSS/0169/096M.

\section{STUDY LIMITATION AND CHALLENGES}

There is no existing available data on child trafficking in Ethiopia and it is challenging to find out the previous data regarding the extent and prevalence of this problem. An absence of accurate data on the extent of child trafficking made more challenged. The lack of data is a global issue, generally, human trafficking is a sensitive issue, which needs more commitment, and patience due to the illegal nature of trafficking, people are unwilling to speak about the subject. Furthermore, the procedure and process to collect data was very challenged, since it is a big sample size research, took a lot of time and resources, more data collectors and involvements, funding was an issue to collect the research.

\section{DATA PRESENTATION AND DISCUSSIONS: PRACTICAL QUALITATIVE STUDY ADOPTION TO ANALYSE CHILD TRAFFICKING}

The main objective of this study is to explore the extent of the trafficked children in number so that it would be easy to understand the magnitude and sensitivity of the problem to respond accordingly.

Table 1: Crosstab Analysis of Child Situation with the Extent of Child Trafficking in Este and Debre Tabor, Ethiopia

\begin{tabular}{|c|c|c|c|c|}
\hline \multicolumn{5}{|c|}{ Crosstabulation of Child trafficking * knows child situation *The situation. } \\
\hline \multicolumn{5}{|c|}{ Count } \\
\hline \multirow{2}{*}{\multicolumn{3}{|c|}{ Child situation }} & Know the child situation & \multirow[b]{2}{*}{ Total } \\
\hline & & & Yes & \\
\hline Working & Child trafficked & Yes & 107 & 107 \\
\hline \multirow{2}{*}{ Learning } & Child trafficked & Yes & 9 & 9 \\
\hline & \multicolumn{2}{|c|}{ Total } & 31 & 31 \\
\hline \multirow[t]{2}{*}{ Both } & Child trafficked & Yes & 12 & 12 \\
\hline & \multicolumn{2}{|c|}{ Total } & 12 & 12 \\
\hline Total & \multicolumn{2}{|c|}{ Total } & 150 & 150 \\
\hline
\end{tabular}


Table 2: Crosstab Analysis of Expectation of Cash vs Child Trafficking

\begin{tabular}{|c|c|c|c|c|c|c|c|}
\hline \multicolumn{8}{|c|}{ Crosstabulation on Child trafficking* Reason for a child to be trafficked * Parent Expectation of cash } \\
\hline \multicolumn{8}{|c|}{ Count } \\
\hline \multicolumn{3}{|c|}{ Parent Expectation of cash } & \multicolumn{4}{|c|}{ Reason for a child to be trafficked } & Total \\
\hline \multirow[t]{2}{*}{ Yes } & \multirow[t]{2}{*}{ Child trafficking } & No & 305 & 8 & 67 & 65 & 445 \\
\hline & & Yes & 94 & 2 & 18 & 38 & 152 \\
\hline \multirow[t]{3}{*}{ No } & \multirow[t]{2}{*}{ Child trafficking } & No & 14 & 1 & 6 & 4 & 25 \\
\hline & & Yes & 7 & 0 & 1 & 6 & 14 \\
\hline & \multicolumn{2}{|l|}{ Total } & 21 & 1 & 7 & \multicolumn{2}{|c|}{1039} \\
\hline Total & Child trafficking & No & 319 & 9 & 73 & 69 & 470 \\
\hline
\end{tabular}

Based on the crosstabulation result of child situation vs the extent of child trafficking, the response rate of the study was 100 percent.

From the total number of 636 respondents, 184 (28.9 percent) have children less than 18 years old who live in town. About 155 respondents (84.2 percent) knew in what condition their children lived. Therefore, according to the crosstabulation analysis result, 107 children (nearly 71.3 percent) were left home for working, 31 (21 percent) left home for learning, and 12 (8 percent) were left home for both working and learning in the different towns. Therefore, from the total number of responses of respondents, about 107 children are trafficked and working in different towns. From this result, it can be concluded that about 128 children had been trafficked in the study area. And the extent of child trafficking is about (20.1 percent) in Este and Debre Tabor, Ethiopia.

Table 2 indicates the relation between family cash expectation and child trafficking. Most parents expect cash income from trafficked children is about 597. Lack of parent's attention and child neglect are also the associate factor for child trafficking, false promises from extended family who leave in the city or sub-city and illegal brokers as a factor for child trafficking is about 38 .

Table 2 indicates the relation between cash expectation by a family member and child trafficking. Most parents expect cash income from trafficked children to be about 597 and in the opposite, some parents don't mind about cash income from their trafficked children is about 39 individuals. However, the parent's cash expectation is positive and as an additional reason for a child to be trafficked from finding and the table indicate that poverty is the factor for the child to be trafficked is about 94 , the lack of attention and neglect is the reason for a child to be trafficked for 2 individuals, lack of social service caused a child to be trafficked for 18 parents and finally the promises from extended family who leave in city or sub-city and illegal brokers cover about 38 parents as a reason for a child to be trafficked.

On, the other side from the parents who have no expectation of benefits in terms of cash but about 7 children are trafficked cause of poverty, and promise from their extended family or brokers as the reason for a child to be trafficked is about 6 children. Generally, about 420 respondents support poverty as a factor for a child to be trafficked and about 11 respondents support lack of attention and neglect of children as the factor for child trafficking, about 92 respondents support the lack of social service as the factor for child trafficking and promises that can be false or true promises as a reason for the child to be trafficked for 113 respondents.

\section{National Response for Child Trafficking}

From the result of the study, it could be concluded that the extent of child trafficking in the study area is high. Similarly, the national response to eradicate the problem of child trafficking in Ethiopia was also investigated. There are measures the Ethiopian government has put in place in trying to fight, control, prevent and address the issue. However, these are not sufficient to deal with this problem, under such 


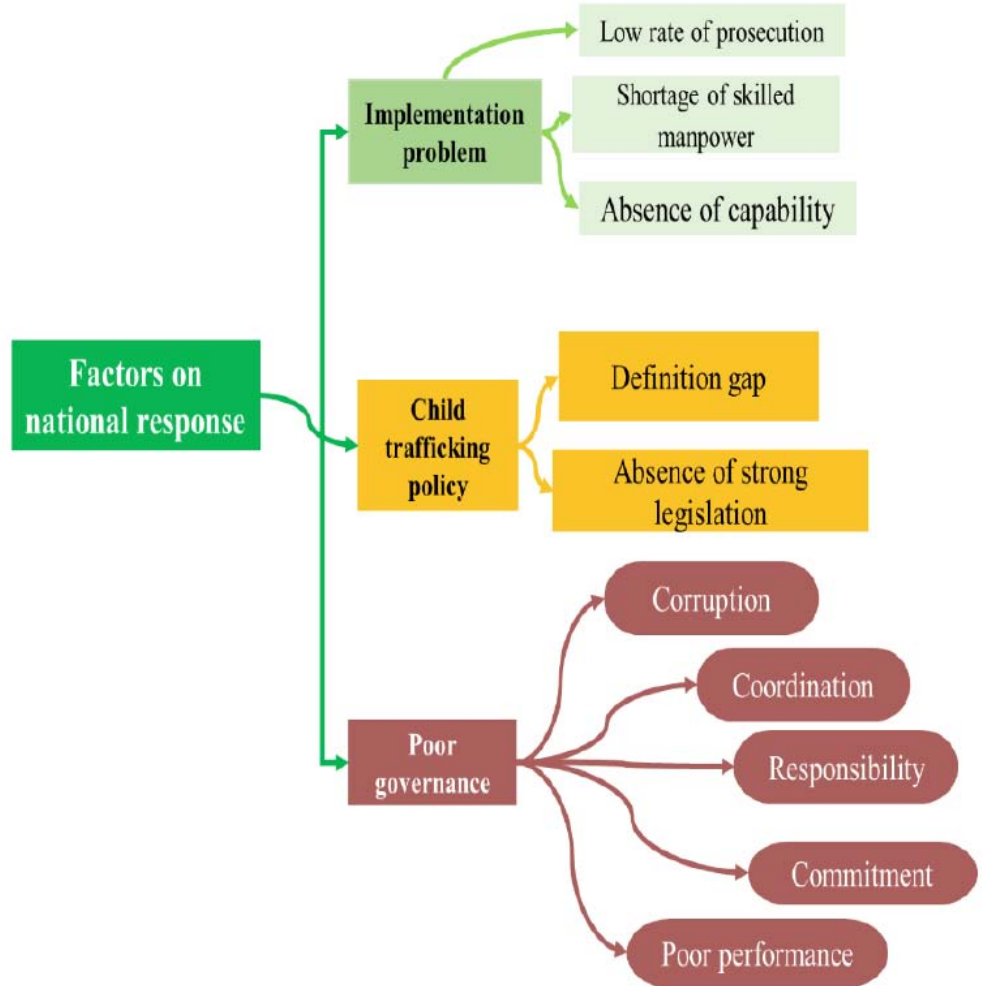

Figure 5: Factors that affect the national response to combat child trafficking in Ethiopian scenario (Tolla, 2017).

conditions since the extent is high. The nation has started making efforts to minimise trafficking; however, it does not completely meet the minimum standards (Office to Monitor and Combat Trafficking in Person, 2016). The implementation problems, poor governance, direct support for the victims, shortage of skilled police to examine child trafficking, official corruption, limited prosecution of traffickers, and limited child trafficking policy, are the main reasons for the unsuccessful progress of child trafficking in Ethiopia. Figure $\mathbf{5}$ factors that affect the national response to combat child trafficking in Ethiopia. This result shows that the national response of the Ethiopian government is deprived. The meaning of trafficking and migration are almost the same and could use interchangeably in Ethiopia since there is no clear information about trafficking in the society. Ethiopia needs to have its conceptualization and understanding of child trafficking.

Therefore, the main concern lies with the government of Ethiopia to ratify the gups to respond to child trafficking appropriately, protect children by implementing legislation accordingly, and encourage prosecution of traffickers and illegal brokers. The Ethiopian government signed almost all the international conventions and treaties, but the problem is still getting worth. Governmental and nongovernmental organizations are working to create awareness about human trafficking. As Ethiopia (2016) revealed that, there is information gup about child trafficking. Poor public awareness about child trafficking causes a low rate of prosecution in Ethiopia. Reports in Ethiopia points to the fact that low rate of prosecution of traffickers needs the attention of police investigation.

\section{CONCLUSIONS}

This paper presented the detailed procedure of research design approach and method for the quantitative research method. The extent of child trafficking is about (20.1 percent) in Este and Debre Tabor, Ethiopia. The sample size of the study population, location of the study, target population, sampling method, research design, method of data collection and method of data analysis, and the validity and reliability of the instruments are deeply discussed. The probability sampling technique was used to select the respondents, which were 636 study respondents were addressed. Systematic random sampling method was used in all parts of the study and the data was analyzed using SPSS.

\section{RECOMMENDATIONS}

From this study researcher suggest further study to be carried in the following area: 
- The data on child trafficking is not available, research is needed to identify the extent of child victims and vulnerable of child trafficking in Ethiopia and Africa, if possible.

- $\quad$ The investigation is needed to address potential socio-cultural, socio-economical, educational, and political factors which contributed to child trafficking in Ethiopia in all 11 regional states to understand the issue in detail.

- $\quad$ On the other hand, for a clear understanding of the International Conventions and Treaties (such as fully translating $\mathrm{CRC}$ and all ratified conventions), the researcher recommended that the publication should be translated to Amharic and Oromifa version (local language) in official Negarit Gazeta of Ethiopia so that everyone could understand and seek to implement their right easily.

- Information gup is a disadvantage for the nation, the government should use different programs on television and radio in the society local language to address the issue.

\section{REFERENCES}

Aden Tolla, A. and Shanta Balgobind Singh 2018. Child trafficking (modern slavery) in Ethiopia: review on status and national. Child Abuse Research: A South African Journal 2018,19(1):58-70.

Aden Tolla, A. and Shanta Balgobind Singh, 2019. The 21st century slavery: an empirical study on contributing push factors for child trafficking in Ethiopia, East Africa. Journal of Alternation Special Edition 28(2019) 278-308. https://doi.org/10.29086/2519-5476/2019/sp28.4a12

Aden Tolla, A. and Shanta Balgobind Singh, 2019. Modern Slavery: An Anthropological Study on the Contributing Pull Factors and National Response of Child Trafficking in Ethiopia, Africa. Journal of Sociology and Social Anthropology (JSSA), 10(1-3): 61-73 (2019) https://doi.org/10.31901/24566764.2019/10-1-3.294

Adepoju, A. (2005). "Review of research and data on human trafficking in sub-Saharan Africa." International Migration 43(1-2): 75-98.

https://doi.org/10.1111/j.0020-7985.2005.00313.x

Agnarson, L. (2006). "The Integration of Ethiopian immigrants in Sweden, 1990-2000."

Aronowitz, A. A. (2009). Human trafficking, human misery: The global trade in human beings, Greenwood Publishing Group.

Assembly, U. G. (2000). "Protocol to prevent, suppress and punish trafficking in persons, especially women and children, supplementing the United Nations convention against transnational organized crime." GA res 55: 25.

Beck, D. C., et al. (2016). "Human Trafficking in Ethiopia: A Scoping Review to Identify Gaps in Service Delivery, Research, and Policy." Trauma, Violence, \& Abuse: 1524838016641670. https://doi.org/10.1177/1524838016641670

Chung, R. C.-Y. (2009). "Cultural perspectives on child trafficking, human rights \& social justice: A model for psychologists." Counselling Psychology Quarterly 22(1): 85-96. https://doi.org/10.1080/09515070902761230
Creswell, J. (2013). Qualitative Inquiry and Research Resign: Choosing Among Five Approaches. (3rd, Ed.) Thousand Oaks, CA: Sage Publication.

Drugs, U. N. O. o., et al. (2009). Global Report on Trafficking in Persons: Human Trafficking a Crime that Shames Us All, United Nations Office on Drugs and Crime.

Endeshaw, Y., et al. (2006). Assessment of Trafficking in Women and Children in and from Ethiopia, IOM, International Organization for Migration.

Fong, R. and J. Berger Cardoso (2010). "Child human trafficking victims: Challenges for the child welfare system." Evaluation and Program Planning 33(3): 311-316. https://doi.org/10.1016/j.evalprogplan.2009.06.018

Hailu, G. K. (2015). "Anti-Human Trafficking Measures in Tigray, Ethiopia: A Human Rights-Based Perspective."

Howard, N. P. (2012). "A critical appraisal of anti-child trafficking discourse and policy in Southern Benin." Childhood: 0907568212444738.

https://doi.org/10.1177/0907568212444738

Lawrance and Roberts (2012) "Trafficking in slavery's wake, law and the experianceof women and children.

Olowu, D. (2002). "Protecting children's rights in Africa: a critique of the African Charter on the Rights and Welfare of the Child." Int'l J. Child. Rts. 10: 127. https://doi.org/10.1163/157181802401005403

Ruane, J. M. (2005). Essentials of Research Methods: A Guide to Social Science Research. Malden, Massachusetts: Blackwell Publishing.

Rosenbaum , P. (2002). Evaluating Multi-Agency Anti-Crime Partnerships: Theory, Design, and Measurement Issues. volume 14, pp.171-225: ResearchGate.

Salah, R. (2004). Child trafficking: a challenge to child protection in Africa. Fourth African Regional Conference on Child Abuse and Neglect. Enugu, March.

Sharon, M., and Ravitch. (2016). Qualitative Research: Bridging the Conceptual, Theoretical, and Methodological. University of Pennsylvania: Sage.

UNICEF (1989). "FACT SHEET: A summary of the rights under the Convention on the Rights of the Child http://www. unicef. org/crc/files." Rights_overview. pdf.

Unicef (1994). The state of the world's children. 1998, Unicef.

UNICEF (2003). "Trafficking in human beings, especially women and children." Africa. Florence: UNICEF Innocenti Research Centre.

UNICEF. (2006). The state of the world's children 2007: Women and children: The double dividend of gender equality, Unicef.

Union, A. (1999). "African Charter on the Rights and Welfare of the Child." Addis ababa, Ethiopia.

Wakgari, G. (2014). "Causes and Consequences of Human Trafficking in Ethiopia: The Case of Women in the Middle East." International Journal of Gender and Women's Studies 2(2): 233-246.

Woldemariam, G. A. (2011). "The predicaments of child victims of crime seeking justice in Ethiopia: a double victimization by the justice process." Africa Focus 24: 11-31. https://doi.org/10.1163/2031356X-02401004

Yosef, Y. P. (2016). "Hearing Whisper of the Child within the Law's Earshot: An Assessment Made on the Legal Bedrocks and International Obligations of Ethiopia toward Article 12 of UNCRC." Beijing Law Review 7(04): 334. https://doi.org/10.4236/blr.2016.74029

Ziebland, S., \& McPherson, A. (2006). Making Sense of Qualitative Data Analysis: An introduction with illustrations from DIPEx (personal experiences of health and illness). Medical Education. https://doi.org/10.1111/j.1365-2929.2006.02467.x 


\section{ONLINE SOURCE REFERENCES}

Abi Bhat, 2020. what is documentary research method? Example, methodology, advantages and disadvantages, 2020. (Online) Available at https://www.questionpro.com/blog/documentaryresearch/. [Accessed on 02/07/2020].

Demographics of Ethiopia, 2017. From Wikipedia, the free encyclopedia, 2017. (Online) Available at https://en.wikipedia.org/ wiki/Demographics_of_Ethiopia [Accessed on 02/10/2017].

Ethiopia, 2016. U.S department of state, Office to monitor and combat trafficking in person's report 2016. (Online) Available at https://www.state.gov/j/tip/rls/tiprpt/countries/2016/ 258765.htm [Accessed on 2/15/2017].

Human rights first, 2017. Human rights first American ideals, universal value, 2017. (Online) Available at https://www.humanrightsfirst.org/topics/human-trafficking [accessed 25/06/2017]

Raimo Streefkerk, 2020. Qualitative vs. quantitative research,2020. (Online) Available at https://www.scribbr.com/methodology/ qualitative-quantitative-research/. [Accessed on 03/07/2020].

Susan E. DeFranzo, 2016. What's the difference between qualitative and quantitative research?, September 16, 2011. (Online) Available at https://www.snapsurveys.com/blog/qualitativevs-quantitative-research/, [Accessed on 04/07/2020].
Trafficking in person, 2019. (Online) Available at https://www.state. gov/wp-content/uploads/2019/06/2019-Trafficking-inPersons-Report.pdf. [Accessed on 07/07/2020].

Trafficking in person, 2018. (Online) Available at https://www.state. gov/wp-content/uploads/2019/01/282798.pdf. [accessed on 06/07/2020].

Save the children, 2017. Children's rights 2017. (Online) Available at http://www.savethechildren.org.uk/about-us/what-wedo/child-rights [Accessed on 6/8/7017].

South Gondar Zone, 2017, From Wikipedia, the free encyclopaedia 2017. (Online) Available at https://en.wikipedia.org/wiki/ South_Gondar_Zone [Accessed on 02/10/2017].

United States department office to monitor and combat trafficking in person, 2015. Office to Monitor and Combat Trafficking in Persons, 2015. (Online) Available at https://www.state. gov/j/tip/ [accessed 25/06/2020].

UNODC, 2016. Report United Nations Office on Drugs and Crime,2016. (online) Available at https://www.unodc.org/ doc/wdr2016/WORLD_DRUG_REPORT_2016_web.pdf [accessed 07/09/2019]

Wings of shelter, 2017. Wings of shelter INT, INC, 2017. (Online) Available at http://www.wingsofshelter.com/in-the-news.html [accessed 25/08/2019].

(C) 2021 Tolla and Singh; Licensee Lifescience Global.

This is an open access article licensed under the terms of the Creative Commons Attribution License (http://creativecommons.org/licenses/by/4.0/) which permits unrestricted use, distribution and reproduction in any medium, provided the work is properly cited. 